\title{
Psychiatric comorbidity of gender identity disorders: A survey among Dutch psychiatrists
}

Citation for published version (APA):

a Campo, J. M. L. G., Nijman, H., Merckelbach, H. L. G. J., \& Evers, C. (2003). Psychiatric comorbidity of gender identity disorders: A survey among Dutch psychiatrists. American Journal of Psychiatry, 160, 1332-1336. https://doi.org/10.1176/appi.ajp.160.7.1332

Document status and date:

Published: 01/01/2003

DOI:

10.1176/appi.ajp.160.7.1332

Document Version:

Publisher's PDF, also known as Version of record

\section{Please check the document version of this publication:}

- A submitted manuscript is the version of the article upon submission and before peer-review. There can be important differences between the submitted version and the official published version of record.

People interested in the research are advised to contact the author for the final version of the publication, or visit the DOI to the publisher's website.

- The final author version and the galley proof are versions of the publication after peer review.

- The final published version features the final layout of the paper including the volume, issue and page numbers.

Link to publication

\footnotetext{
General rights rights.

- You may freely distribute the URL identifying the publication in the public portal. please follow below link for the End User Agreement:

www.umlib.nl/taverne-license

Take down policy

If you believe that this document breaches copyright please contact us at:

repository@maastrichtuniversity.nl

providing details and we will investigate your claim.
}

Copyright and moral rights for the publications made accessible in the public portal are retained by the authors and/or other copyright owners and it is a condition of accessing publications that users recognise and abide by the legal requirements associated with these

- Users may download and print one copy of any publication from the public portal for the purpose of private study or research.

- You may not further distribute the material or use it for any profit-making activity or commercial gain

If the publication is distributed under the terms of Article $25 \mathrm{fa}$ of the Dutch Copyright Act, indicated by the "Taverne" license above, 


\section{Psychiatric Comorbidity of Gender Identity Disorders: A Survey Among Dutch Psychiatrists}

\author{
Joost à Campo, M.D. \\ Henk Nijman, Ph.D. \\ H. Merckelbach, Ph.D. \\ Catharine Evers, M.Sc.
}

\begin{abstract}
Objective: In the Netherlands, it is considered good medical practice to offer patients with gender identity disorder the option to undergo hormonal and surgical sex reassignment therapy. A liberalization of treatment guidelines now allows for such treatment to be started at puberty or prepuberty. The question arises as to what extent gender identity disorder can be reliably distinguished from a cross-gender identification that is secondary to other psychiatric disorders.
\end{abstract}

Method: The authors sent survey questionnaires to 382 board-certified Dutch psychiatrists regarding their experiences with diagnosing and treating patients with gender identity disorder.

Results: One hundred eighty-six psychiatrists responded to the survey. These respondents reported on 584 patients with cross-gender identification. In 225 patients
(39\%), gender identity disorder was regarded as the primary diagnosis. For the remaining 359 patients (61\%), cross-gender identification was comorbid with other psychiatric disorders. In 270 (75\%) of these 359 patients, cross-gender identification was interpreted as an epiphenomenon of other psychiatric illnesses, notably personality, mood, dissociative, and psychotic disorders.

Conclusions: These data suggest that there is little consensus, at least among Dutch psychiatrists, about diagnostic features of gender identity disorder or about the minimum age at which sex reassignment therapy is a safe option. Therapy options proposed to patients with gender identity disorder appear to depend on personal preferences of psychiatrists. These results underline the need for more specific diagnostic rules in this area.

(Am J Psychiatry 2003; 160:1332-1336)

A characterized by a strong and persistent cross-gender identification and persistent discomfort with one's own sex. With an estimated worldwide lifetime prevalence of $0.001 \%-0.002 \%$, gender identity disorder is rare (1). However, the prevalence of gender identity disorder appears to be higher in the Netherlands. Here, male-to-female gender identity disorder is found in about 1 per 12,000 inhabitants and female-to-male gender identity disorder is seen in 1 per 30,000 (2).

About two-thirds of the patients referred to Dutch gender clinics are given the opportunity to undergo hormonal therapy; many are also offered surgical sex reassignment therapy. In line with the liberal tradition of the Netherlands, there appears to be no serious opposition against this invasive treatment for patients with gender identity disorder. Dutch research suggests that patients with gender identity disorder generally benefit from sex reassignment therapy (3), although studies from other countries (4-6) report somewhat higher percentages of patients regretting their sex reassignment therapy (i.e., about $10 \%-20 \%)$.

Recently, treatment guidelines for gender identity disorder have been further liberalized in the Netherlands; the new guidelines allow patients in puberty or prepuberty to apply for sex reassignment therapy. During the first phase of this therapy, patients receive hormones blocking their normal sexual maturation (7). At age 16, actual sex reassignment starts by administration of hormones of the desired sex (i.e., estrogens for male-to-female and androgens for female-to-male patients). Each year, about 10 youngsters receive this treatment regimen (7). However, a potential problem with lowering the age for sex reassignment procedures is that it may increase the risk of false positive diagnoses.

A case in point is schizophrenia, a condition that cannot be diagnosed with reasonable certainty until early adulthood. DSM-IV states that "delusions of belonging to the other sex" (p. 537) are rarely seen in schizophrenia, but this claim is difficult to reconcile with studies showing that about $25 \%$ of patients with schizophrenia experience cross-gender identification at some point in their life (811). In line with this, for a diagnosis of gender identity disorder (previously termed "transsexualism"), DSM-III required that the symptoms were "not due to another mental disorder, such as Schizophrenia” (p. 264). Later editions of DSM have dropped this exclusion criterion. However, when it comes to diagnostic criteria for other disorders involving body image (e.g., body dysmorphic disorder), DSM-IV emphasizes that concomitant psychiatric dis- 
orders have to be ruled out. DSM-IV acknowledges that omission of this exclusion criterion creates the possibility that "Schizophrenia and severe Gender Identity Disorder may coexist" in the same patient but adds that such comorbidity is unlikely (p. 537).

That the diagnostic differentiation between gender identity disorder and schizophrenia might sometimes be difficult is illustrated by a patient who was referred to one of us (J.àC.) (12). For a period of 6 years, this patient had been treated with hormones in a gender reassignment center. While being scheduled for gender reassignment surgery, the patient was referred to our psychiatric facility because of a psychotic decompensation. He was diagnosed as suffering from schizophrenia of the paranoid type, and when he was given neuroleptic medication his psychotic symptoms decreased and his feelings of being a woman in a man's body disappeared. In retrospect, it appears that this patient interpreted his cross-gender confusion as part of his delusional thinking. Although he is now doing well on a regimen of antipsychotic drugs and lives in the community, he deeply regrets the hormonal treatment and suffers from its irreversible side effects (e.g., atrophy of the genitals and female breasts).

This case suggests that cross-gender delusions in patients with schizophrenia may mimic the persistent and stable cross-gender identification seen in patients with gender identity disorder. The psychiatric literature offers several anecdotal reports of cases in which cross-gender identification disappeared when patients were treated with antipsychotic medication (12-17). There are also case descriptions of patients whose cross-gender identification returned after antipsychotic medication was stopped (18). Finally, there are reports of remission of gender identity disorder in nonpsychotic, nonmedicated adult patients (19). The supporting text for the DSM-IV gender identity disorder criteria assumes that a patient with genuine gender identity disorder "feels like a member of the other sex rather than truly believes that he or she is a member of the other sex" (p. 537). In many cases, this clinical heuristic might be useful, but the example cited here suggests that it sometimes fails.

When patients with gender identity disorder suffer from severe comorbid psychopathology, it may be difficult for psychiatrists to decide which diagnosis should have a primary status. It is obvious that, in such cases, any decision has far-reaching consequences for the type of treatment selected and for the well-being of the patients involved. How often are psychiatrists confronted with cross-gender identification cases in which diagnostic complications arise? To address this issue, we assessed current opinions about comorbidity and treatment of gender identity disorder in a national sample of board-certified psychiatrists.

\section{Method}

From the records of the Dutch Psychiatric Association, we randomly selected 382 psychiatrists. In July 2000, these psychiatrists were sent an 11-item questionnaire that asked them whether they had ever treated patients who experienced cross-gender confusion (Appendix 1). When they said they had, psychiatrists were asked to specify, for each case they had treated, whether they judged gender identity disorder to be the primary diagnosis or the cross-gender confusion was interpreted and treated as secondary to other psychiatric conditions. Additionally, several questions addressing the psychiatrists' opinions about diagnosing and treating gender identity disorder were asked. The final item invited respondents to comment freely on the issue.

\section{Results}

Of the 382 psychiatrists, 186 (49\%) completed and returned the questionnaire before the deadline of September 29, 2000. Respondents had been working as psychiatrists for a mean of 13.9 years $(\mathrm{SD}=7.4$, range $=0.5-31.0)$.

\section{Experiences With Cross-Gender Confusion and Gender Identity Disorder}

A large majority of the respondents $(76 \%$ [N=142]) had treated cross-gender confused patients at least once. The total number of patients treated varied from 0 to 50 per psychiatrist. As anticipated, there was a modest but significant correlation between years of working experience and number of patients treated (Pearson's $\mathrm{r}=0.15, \mathrm{~N}=186$, $\mathrm{p}<0.05)$. In total, the 186 respondents reported about 584 patients suffering from cross-gender confusion. When this rate is generalized to the entire population of Dutch psychiatrists, it would mean that Dutch psychiatrists are consulted every 4.5 years by a patient who experiences crossgender confusion.

In 225 (39\%) of the 584 reported cases, gender identity disorder was regarded as the primary diagnosis. For the remaining 359 patients $(61 \%)$, cross-gender confusion occurred along with other psychiatric disorders, and in 270 (75\%) of these 359 cases, it was interpreted as secondary to other psychiatric illnesses.

\section{Nature of Psychiatric Comorbidity}

One hundred twenty-nine psychiatrists specified psychiatric comorbidity for their patients with gender identity disorder. Comorbid personality disorders were reported by 102 (79\%) of the 129 psychiatrists, major mood disorders by 34 (26\%), dissociative disorders by 34 (26\%), and psychotic disorders by 31 (24\%).

We asked psychiatrists whether they agreed with the DSM-IV heuristic not to rule out other disorders in cases where a gender identity disorder diagnosis is considered. One hundred seventy-seven of the 186 respondents answered this question; 38 (21\%) of these respondents indicated that they were not able to make up their mind about this issue. Of the 139 psychiatrists who did express an opinion, 78 (56\%) considered this heuristic not to be wise. 


\section{Treatment}

Of the 142 psychiatrists who had treated patients with cross-gender confusion, 40 (28\%) had referred patients to specialized gender clinics for further treatment at least once. These 40 psychiatrists had referred 73 patients (range $=1-15)$ to sex reassignment therapy facilities. The large majority of the referring psychiatrists $(75 \%[\mathrm{~N}=30])$ had referred only one patient to a gender clinic. Thus, the remaining group of 10 psychiatrists was responsible for the majority of referrals to gender clinics (i.e., 43 [59\%] of the 73 referrals).

Only 95 (51\%) of the 186 respondents were willing to specify an appropriate age for starting gender reassignment therapy. One psychiatrist said that gender reassignment should not be considered until the patient reaches the age of 85. After exclusion of this curious outlier, the mean recommended starting age was 18.7 years $(\mathrm{SD}=3.9$, range $=10-25)$.

\section{Discussion}

A majority of Dutch psychiatrists reported that they had encountered patients with cross-gender confusion at least once. This finding should be interpreted with caution because of limitations inherent to surveys. Although psychiatrists were randomly selected and the response rate was acceptable (49\%), it may be that psychiatrists who did not have any experience with such patients were less inclined to return the questionnaire. Apart from that, we cannot rule out that the reported patient cases included duplications: some patients may have been treated by more than one of the responding psychiatrists.

In spite of these limitations, the conclusion seems warranted that at some point in their career, most Dutch psychiatrists will be consulted by a patient suffering from cross-gender confusion. Therefore, it is important that there be consensus about the diagnostic procedures and treatment options that should be considered for such patients. Our results, however, suggest that opinions differ as to the type of treatment that should be considered first in these cases. A small number of psychiatrists seem to refer such patients to specialized sex reassignment therapy centers on a regular basis, but others never seem to recommend this treatment route. It appears that the therapy options proposed to patients with gender identity disorder depend heavily on the personal preferences of psychiatrists. Thus, one respondent said he had referred 15 patients to a gender clinic, but another remarked that "the scalpel should not be used to reconcile fantasy with reality." The view of this latter respondent corresponds to that of McHugh (20), who noted that it is hard to understand how the belief of a male patient "that he is a woman trapped in a man's body differs from the feelings of a patient with anorexia nervosa that she is obese despite her emaciated, cachectic state. We don't do liposuction on an- orexics. So why amputate the genitals of these patients?" (p. 111).

Opinions also differed with regard to diagnostic routines and the minimum age for sex reassignment therapy to be a safe treatment. Almost half of the respondents were not willing to specify a minimum starting age for such treatment. The average minimum age specified by respondents who were willing to answer this question was well above the legally permissible age for this procedure in the Netherlands.

Personality, mood, dissociative, and psychotic disorders were the most often reported psychiatric conditions comorbid with gender identity disorder. In about half of the cases that were reported, cross-gender confusion was regarded as an epiphenomenon of other illnesses. Although psychiatrists probably see a self-selected group of patients with cross-gender confusion (those with psychiatric problems would be more likely to visit a psychiatrist), these results underline the need for education of general physicians about psychiatric comorbidity of cross-gender identification.

Our findings also underline the need for articulated diagnostic rules in this area. A nontrivial proportion of our respondents felt that the current DSM-IV gender identity disorder criteria are not strict enough. These respondents indicated that other psychiatric disorders that may explain the cross-gender symptoms should be ruled out before considering a diagnosis of gender identity disorder. There is evidence suggesting that persistent cross-gender identification may occur in psychotic patients. In such cases, the cross-gender confusion appears to be entirely attributable to the misperception of reality that is typical for psychotic disorders (12-18).

Our results, together with anecdotal reports about gender identity disorder misdiagnoses, indicate that it may be fruitful to consider reinstatement of an exclusion criterion that cross-gender symptoms should not be attributable to other psychiatric disorders such as schizophrenia. The current DSM criteria allow for a situation in which gender identity disorder and schizophrenia "may coexist" in a patient (DSM-IV, p. 537). One of our respondents said, "When a patient has an acute psychotic episode, I wouldn't dare to diagnose gender identity disorder."

The fact that psychosis is mentioned relatively often as a comorbid problem of gender identity disorder also calls for a very careful evaluation of the benefits and risks involved in lowering the starting age for sex-adjustment treatment. The more florid symptoms of psychotic disorders generally do not emerge until adolescence and early adulthood. Confusion about one's identity, body image aberrations, and the wish to drastically change one's appearance (e.g., references 21, 22), however, may become manifest before actual psychotic breakdown occurs, as was the case in our hormonally treated psychotic patient (12). Discussions about the proper age for starting sex reassignment therapy should take into account the far- 
reaching consequences of misclassifying psychotic patients' cross-gender confusion as gender identity disorder. Thus, in order to assess reliably the nature of the expressed desire to change gender, it may be necessary to wait until early adulthood before sex reassignment ther- apy becomes a safe option. We feel that independent committees that monitor and evaluate referrals to sex reassignment therapies would be of benefit in this area. Psychiatrists should be well represented on such committees.

APPENDIX 1. Cross-Gender Treatment Survey Questions

1. How many years have you been working as a psychiatrist?

2. In your career as a psychiatrist, how many times have you dealt with patients with cross-gender confusion?

3. For how many of these patients did you establish gender identity disorder as a primary diagnosis?

4. For how many of these patients did you judge the cross-gender identification to be secondary to other DSM-IV diagnoses?

5. In how many of your patients with gender identity disorder did comorbid psychiatric disorders exist?

6. If you have experience with patients suffering from gender identity disorder in combination with comorbid psychiatric disorders, what comorbid disorders were those?

years

times

patients

patients

patients

Personality disorders

Adjustment disorders

Impulse control disorders

Eating disorders

Sexual disorders

Dissociative disorders

Factitious disorders

Somatoform disorders

Anxiety disorders

Mood disorders

Schizophrenia and other psychotic disorders

Substance-related disorders

Mental disorders due to a general medical condition

Delirium, dementia, and amnestic and other cognitive disorders

7. Did you ever refer a patient to a gender reassignment center? No (skip to question 9)

Yes,

Yes

No

Not sure

Yes

years

10. What in your opinion is an appropriate age to start sex reassignment therapy?

11. Do you wish to comment further on this issue?

Received May 29, 2002; revision received Oct. 2, 2002; accepted Jan. 22, 2003. From Mondriaan Zorggroep Hospital; Forensic Psychiatric Hospital Kijvelanden, Poortugaal, the Netherlands; the Department of Experimental Psychology, Maastricht University, Maastricht, the Netherlands; and the Department of Social Psychology of the University of Amsterdam, the Netherlands. Address reprint requests to Dr. à Campo, Mondriaan Zorggroep Hospital, P.O. Box 4436, 6401 CX Heerlen, the Netherlands; camrep@planet.nl (e-mail).

\section{References}

1. Roberto G: Issues in diagnosis and treatment of transsexualism. Arch Sex Behav 1983; 12:445-473

2. Bakker A, Van Kesteren PM, Gooren LJ, Bezemer PD: The prevalence of transsexualism in the Netherlands. Acta Psychiatr Scand 1993; 87:237-238

3. Cohen-Kettenis P, van Goozen S: Sex reassignment of adolescent transsexuals: a follow-up study. J Am Acad Child Adolesc Psychiatry 1997; 36:263-271

4. Sörensen T: A follow-up study of operated transsexual males. Acta Psychiatr Scand 1981; 63:486-503

5. Lindemalm G, Körlin D, Uddenberg N: Long-term follow-up of "sex change" in 13 male-to-female transsexuals. Arch Sex Behav 1986; 15:187-210
6. Bodlund O, Kullgren G: Transsexualism-general outcome and prognostic factors: a five year follow-up study of nineteen transsexuals in the process of changing sex. Arch Sex Behav 1996; 25:303-316

7. Cohen-Kettenis P, Dillen C, Gooren L: De behandeling van jonge transseksuelen in Nederland [The treatment of young transsexual patients in the Netherlands]. Ned Tijdschr Geneeskd 2000; 144:698-702

8. Lukianowicz L: Transvestism and psychosis. Psychiatr Neurol (Basel) 1995; 138:67-78

9. Gittleson NL, Levine S: Subjective ideas of sexual change in male schizophrenics. Br J Psychiatry 1966; 112:779-782

10. Gittleson NL, Dawson-Butterworth K: Subjective ideas of sexual change in female schizophrenics. Br J Psychiatry 1967; 113: 491-494

11. Connolly F, Gittleson N: The relationship between delusions of sexual change and olfactory and gustatory hallucinations in schizophrenia. Br J Psychiatry 1971; 119:443-444

12. à Campo J, Nijman HL, Evers C, Merckelbach H, Decker I: Genderidentiteitsstoornissen als bijverschijnsel van psychose, in het bijzonder schizofrenie [Gender identity disorders as comorbid phenomena of psychosis and schizophrenia]. Ned Tijdschr Geneeskd 2001; 39:1876-1880

13. O'Gorman E: The effect of psychosis on gender identity. $\mathrm{Br}$ J Psychiatry 1980; 136:314-315 


\section{GENDER IDENTITY DISORDERS}

14. Commander M, Dean C: Symptomatic transsexualism. Br J Psychiatry 1990; 156:894-896

15. Faulk M: Psychosis in a transsexual. Br J Psychiatry 1990; 156 : 285-286

16. Caldwell C, Keshavan MS: Schizophrenia with secondary transsexualism. Can J Psychiatry 1991; 36:300-301

17. Cuypere de G: Schizophrenia and symptomatic transsexualism, two case reports. Eur Psychiatry 1993; 8:163-167

18. Puri BK, Singh I: The successful treatment of a gender dysphoric patient with pimozide. Aust NZ J Psychiatry 1996; 30: 422-425
19. Marks I, Green R, Mataix-Cols D: Adult gender identity disorder can remit. Compr Psychiatry 2000; 41:273-275

20. McHugh PR: Witches, multiple personalities, and other psychiatric artifacts. Nat Med 1995; 1:110-114

21. à Campo J, Nijman HL, Merckelbach HL, Yeates-Frederikx MH: Changes in appearance and psychosis. Psychiatry 2001; 64: 165-167

22. à Campo J, Frederikx M, Nijman H, Merckelbach H: Schizophrenia and changes in physical appearance (letter). J Clin Psychiatry 1998; 59:197 